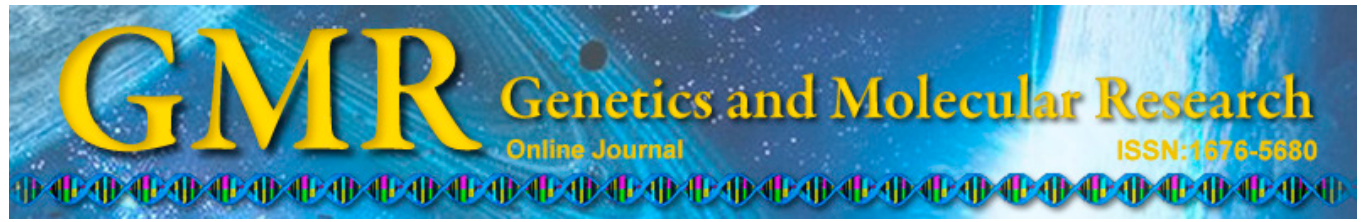

\title{
Effects of silver nanoparticles and gold nanoparticles on IL-2, IL-6, and TNF- $\alpha$ production via MAPK pathway in leukemic cell lines
}

\author{
C. Parnsamut ${ }^{1}$ and S. Brimson ${ }^{2}$ \\ ${ }^{1}$ Graduate Program in Clinical Hematology Sciences, \\ Department of Clinical Microscopy, Faculty of Allied Health Sciences, \\ Chulalongkorn University, Bangkok, Thailand \\ ${ }^{2}$ Center for Research and Development in Molecular Hematology Sciences, \\ Department of Clinical Microscopy, Faculty of Allied Health Sciences, \\ Chulalongkorn University, Bangkok, Thailand
}

Corresponding author: S. Brimson

E-mail: Sirikalaya.J@chula.ac.th

Genet. Mol. Res. 14 (2): 3650-3668 (2015)

Received March 26, 2014

Accepted August 1, 2014

Published April 17, 2015

DOI http://dx.doi.org/10.4238/2015.April.17.15

ABSTRACT. Silver nanopaticles (AgNPs) and gold nanoparticles
(AuNPs) have various applications in medical healthcare and various
biological properties such as anti-inflammation, anti-cancer, and anti-
angiogenesis. In this study, we investigated the effect of AgNPs and
AuNPs on cytokine production via the mitogen-activated protein kinase
pathway in leukemic cell lines (T-lymphocytic Jurkat and monocytic
U937 cells). We found that both AgNPs and AuNPs inhibited cell
proliferation of leukemic cell lines. AgNPs inhibited TNF- $\alpha$, while
AuNPs inhibited interleukin-2 production in Jurkat cells, in which
inhibition of cytokines is involved in the extracellular-signal regulated
protein kinase but not the c-Jun N-terminal kinase pathway. In U937
cells, AuNPs inhibited interleukin- 6 but stimulated TNF- $\alpha$ production in 
a concentration-dependent manner through the c-Jun N-terminal kinase but not the extracellular-signal regulated protein kinase pathway. Our study showed that each leukemic cell line treated with nanoparticles exhibited a distinct signaling pathway response to inhibit or stimulate cytokine production, leading to anti-cell proliferation. The effects of AgNPs and AuNPs on leukemic cell lines may have a significant impact on leukemia treatment in the future.

Key words: C-Jun N-terminal kinase; Extracellular receptor kinase; Cytokines; Jurkat; Silver-gold nanoparticles; U937

\section{INTRODUCTION}

Leukemia is a form of malignancy that occurs in the blood, and thus is known as blood cancer. In this disease, abnormal hematopoietic stem cells are present in the bone marrow, which causes abnormal proliferation and differentiation as well as an increased number of immature white blood cells (Piller, 2003; Brown et al., 2012). Patients suffering from leukemia are treated with chemotherapy; however, chemotherapy causes a number of side effects. Thus, other options have been developed to treat leukemia and reduce these side effects.

Nanoparticles have many applications and are studied an important area of research known as nanotechnology. In this study, we chose silver nanoparticles (AgNPs) and gold nanoparticles (AuNPs) as an alternative treatment method that may reduce side effects. AgNPs and AuNPs are the most commonly used nanotechnology and have numerous applications in medical healthcare. They have various biological properties, including anti-microbial (Panácek et al., 2009; Alarcon et al., 2012), anti-inflammatory (Wong et al., 2009), and antiangiogenesis properties (Arvizo et al., 2011). AgNPs and AuNPs upregulate the expression of the proinflammatory genes interlukin-1 (IL-1), interlukin-6 (IL-6), and tumor necrosis factor (TNF- $\alpha$ ) in macrophage cells (Yen et al., 2009). Furthermore, AuNPs have been shown to significantly increase the expression of IL- 6 and TNF- $\alpha$ in the kidneys of rats (Khan et al., 2013). Cytokines are signaling molecules that mediate and regulate cellular activities. Proinflammatory cytokines such as IL-2, IL-6, and TNF- $\alpha$ regulate immunity, inflammation, and hematopoiesis (O'Shea et al., 2008). Cytokines are important for the mitogen-activated protein kinase (MAPK) pathway, which is one of many pathways that require cytokines for proper functioning (Kyriakis and Avruch, 2001).

MAPK pathway proteins contain conserved activation sites and structures that link extracellular signals to the machinery that controls fundamental cellular processes, such as growth, proliferation, differentiation, migration, and apoptosis (Chang and Karin, 2001; Platanias, 2003). Groups of MAPKs have been characterized in mammals, including extracellular signal regulated protein (ERK), c-Jun N-terminal kinase (JNK), and the p38 MAPK (Dhillon et al., 2007). In previous studies, AgNPs exposure activated p38 MAPK through the nuclear factor-E2-related factor-2 and nuclear factor-kappaB (NF-kB) signaling pathways, subsequently inducing DNA damage, cell cycle arrest, and apoptosis in Jurkat cells (Eom and Choi, 2010). Furthermore, apoptosis has been associated with the generation of reactive oxygen species and JNK activation was induced in NIH3T3 cells (Hsin et al., 2008). AuNPs activates p38 MAPK by regulating the expression of genes to induce osteogenic differentiation in mesenchymal stem cells (Yi et al., 2010). 
In the present study, we investigated the effects of AgNPs and AuNPs on IL-2, IL-6, and TNF- $\alpha$ production via MAPK pathways in human leukemic cell lines (Jurkat and U937). We hypothesized that changes in MAPKs activity and expression, induced by nanoparticles, would influence cytokine production in leukemic cells. Our results may be applied for AgNPs and AuNPs in the treatment of leukemia.

\section{MATERIAL AND METHODS}

\section{Nanoparticles preparation}

In this study, gold and silver nanoparticles were synthesized using the chemical reduction method, also known as the Turkevich method, using trisodium citrate (Fluka, Buchs, Switzerland). Nanoparticles were synthesized as stock solution at a maximum concentration of $500 \mathrm{ppm}$. The nanoparticles were estimated to range from 10-50 nm in diameter (Turkevich et al., 1951; Eustis, 2006).

\section{$\operatorname{AgNPs}$}

AgNPs were prepared from an aqueous $50 \mathrm{~mL}$ solution of $0.001 \mathrm{M} \mathrm{AgNO}_{3}$ (Sigma Aldrich, St. Louis, MO, USA), which was heated to boiling point and stirred using a magnetic stirrer. Next, $5 \mathrm{~mL} \mathrm{1 \%} \mathrm{trisodium} \mathrm{citrate} \mathrm{was} \mathrm{added} \mathrm{dropwise.} \mathrm{The} \mathrm{AgNP} \mathrm{solution} \mathrm{color}$ changed from clear to yellow. Stirring was continued until the solution had cooled to room temperature. Finally, a drop of $0.3 \%$ polyvinyl pyrrolidone (PVP) (Sigma Aldrich) was added to prevent aggregation (Wang et al., 2005; Solomon et al., 2007).

\section{AuNPs}

AuNPs were prepared from $20 \mathrm{~mL} 0.001 \mathrm{M} \mathrm{HAuCl}_{4}$ (Sigma Aldrich). This solution was heated to boiling on a magnetic stirrer. To the rapidly stirred boiling solution, $2 \mathrm{~mL} 1 \%$ trisodium citrate was added. The AuNP solution color changed from the original yellow to a deep red color. It was then stirred until cooled to room temperature. Finally, a drop of $0.3 \%$ PVP was added to prevent aggregation.

\section{Cell culture}

The human leukemic T cell line Jurkat (ATCC, Manassas, VA, USA) was cultured in RPMI-1640 (Hyclone, Logan, UT, USA) supplemented with 10\% fetal bovine serum, plated in 12-well plates, and incubated overnight at $37^{\circ} \mathrm{C}$ with $5 \% \mathrm{CO}_{2}$.

The human monocytic cell line U937 (ATCC) was cultured in RPMI 1640 (Hyclone) supplemented with $10 \%$ fetal bovine serum. U937 cells were activated with $10 \mathrm{nM}$ phorbol 12-myristate 13-acetate (PMA) (Sigma Aldrich), seeded on 12-well plates, and incubated overnight at $37^{\circ} \mathrm{C}$ with $5 \% \mathrm{CO}_{2}$.

\section{Cell viability assay}

Cell viability was evaluated using a modified XTT assay kit (Sigma Aldrich). Jurkat 
and U937 cells were seeded at a density of $1 \times 10^{6}$ cells $/ \mathrm{mL}$ in complete RPMI medium on 96-well plates and treated with AgNPs (2.5-15 ppm), AuNPs (5-50 ppm), and vehicle control (sodium citrate and PVP) incubated at $37^{\circ} \mathrm{C}$ in a humidified atmosphere with $5 \% \mathrm{CO}_{2}$ for 24 $\mathrm{h}$. Untreated cells were used as a negative control and dimethyl sulfoxide was used as a positive control. After $24 \mathrm{~h}, 20 \mu \mathrm{L}$ XTT working solution was added to each well and the plates were incubated for $4 \mathrm{~h}$. Absorbance was measured using a microtiter plate reader (BioTek, Winsooki, VT, USA) at a wavelength of $450 \mathrm{~nm}$ and a reference $690 \mathrm{~nm}$. The relative cell viability (\%) related to control wells containing cells without nanoparticles was calculated using the following equation: $[\mathrm{A}]_{\text {test }} /[\mathrm{A}]_{\text {control }} \times 100$.

\section{Enzyme-linked immunosorbent assay (ELISA) of IL-2, IL-6, and TNF- $\alpha$}

Jurkat cells $\left(1 \times 10^{6} / \mathrm{mL}\right)$ were treated with AgNPs, with concentrations ranging from 0-7.5 ppm and various concentrations of AuNPs from 0-30 ppm. As a positive control, $12.5 \mathrm{ng} /$ mL PMA plus $0.25 \mu \mathrm{g} / \mathrm{mL}$ lectin from Phaseolus vulgaris/Leucoagglutinin (PHA-L) (Sigma Aldrich) were used to stimulate control cells. The cells were incubated at $37^{\circ} \mathrm{C}$ with $5 \% \mathrm{CO}_{2}$ for $12 \mathrm{~h}$ before the addition of PMA/PHA and were then incubated for additional $12 \mathrm{~h}$. Cells were incubated for a total of $24 \mathrm{~h}$ with various concentrations of AgNPs, AuNPs, or PMA/PHA. After the incubation, culture media was collected for detection of IL-2 and TNF- $\alpha$ levels.

U937 cells $\left(1 \times 10^{6} / \mathrm{mL}\right)$ were treated with AgNP concentrations ranging from 0-7.5 $\mathrm{ppm}$ and various concentrations of AuNPs from 0-30 ppm. As a positive control, $1 \mu \mathrm{g} / \mathrm{mL}$ lipopolysaccharide (LPS) (Sigma-Aldrich) was used to activate control cells. The cells were incubated at $37^{\circ} \mathrm{C}$ with $5 \% \mathrm{CO}_{2}$ for $12 \mathrm{~h}$ before stimulation with LPS and then incubated for additional $12 \mathrm{~h}$. Cells were incubated for a total of $24 \mathrm{~h}$ with various concentrations of AgNPs, AuNPs, or LPS. Following incubation, culture media was collected for detection of IL-6 and TNF- $\alpha$ levels. In addition to the experimental wells, $1 \%$ sodium citrate and $0.3 \%$ PVP was used as a vehicle control.

Cytokines release (IL-2, IL-6, and TNF- $\alpha$ ) of AgNP- and AuNP-treated cells were quantified using an ELISA kit (R\&D Systems, Minneapolis, MN, USA) and absorbance measured using a microtiter plate reader (Perkin Elmer, Waltham, MA, USA) at a wavelength of $450 \mathrm{~nm}$ with a reference $540 \mathrm{~nm}$. The cytokine level was normalized to the total protein concentration of cell pellets using the Bradford method with the Bio-Rad protein assay reagent (Bio-Rad, Hercules, CA, USA).

\section{Western blot analysis}

Jurkat cells and U937 cells $\left(1 \times 10^{6} / \mathrm{mL}\right)$ were treated with $7.5 \mathrm{ppm}$ AgNPs, $25 \mathrm{ppm}$ AuNPs, and vehicle control (sodium citrate and PVP) for different time periods ranging from $0-24 \mathrm{~h}$ in triplicate. Both cell lines were collected and washed with phosphate-buffered saline, $\mathrm{pH}$ 7.4, 3 times. Cellular lysate was prepared using lysis buffer containing $25 \mathrm{mM}$ Tris-phosphate, $\mathrm{pH}$ 7.8, $2 \mathrm{mM}$ dithiothreitol, $2 \mathrm{mM}$ 1,2-diaminocyclohexane-N,N,N',N'-tetraacetic acid, $10 \%$ glycerol, $1 \%$ Triton ${ }^{\circledR}$ X-100, and added protease inhibitor cocktail (Sigma-Aldrich). An equivalent amount of sample was separated by $10 \%$ sodium dodecyl sulfate-polyacrylamide gel electrophoresis and transferred to a polyvinylidene difluoride membrane (Millipore, Billerica, MA, USA). The membrane was blocked for $1 \mathrm{~h}$ at room temperature with Tris-buffered saline containing $5 \%$ non-fat milk. Next, the membranes were incubated overnight at $4{ }^{\circ} \mathrm{C}$ with 
the primary antibody diluted 1:1000-4000 against p-ERK1/2, ERK1/2, p-SAPK/JNK, SAPK/ JNK, and $\beta$-actin (Cell Signaling, Danvers, MA, USA) and then incubated with horseradish peroxidase-conjugated secondary antibody 1:2000-4000 (Cell Signaling) for $45 \mathrm{~min}$. After application of the secondary antibody, triplicate washes with Tris-buffered saline containing Tween 20 were conducted. Finally, visualization of protein expression was achieved using enhanced chemiluminescence western blotting substrate (Pierce, Rockford, IL, USA) before exposure to Hyperfilm-enhanced chemiluminescence (GE Healthcare, UK). Densitometry analysis was carried out using the NIH ImageJ software (Bethesda, MD, USA).

\section{Statistical analysis}

Statistical analyses were assessed by one-way analysis of variance. The Graph Pad Prism software version 4.00 (Graph Pad Software Inc., San Diego, CA, USA) was used. A P value $<0.05$ was considered to be significant.

\section{RESULTS}

\section{Inhibition of leukemic cell lines proliferation by AgNPs and AuNPs}

In this study, we examined whether AgNPs and AuNPs inhibited the proliferation of leukemic cells (Jurkat and U937) in a concentration-dependent manner. Cells were treated with AgNPs (2.5-15 ppm) and AuNPs (5-50 ppm) for $24 \mathrm{~h}$ and cell viability was analyzed using the XTT assay. The results are reported as means \pm standard error from 3 independent experiments. The results showed that proliferation inhibition of leukemic cells was dose-dependent with a median inhibition concentration $\left(\mathrm{IC}_{50}\right.$ value $)$ of AgNPs of 9.8 and $12.6 \mathrm{ppm}$ in Jurkat cells and U937 cells, respectively (Figure 1). The $\mathrm{IC}_{50}$ of AuNPs in Jurkat cells was 43.3 ppm and of U937 cells was 45.6 ppm (Figure 2).

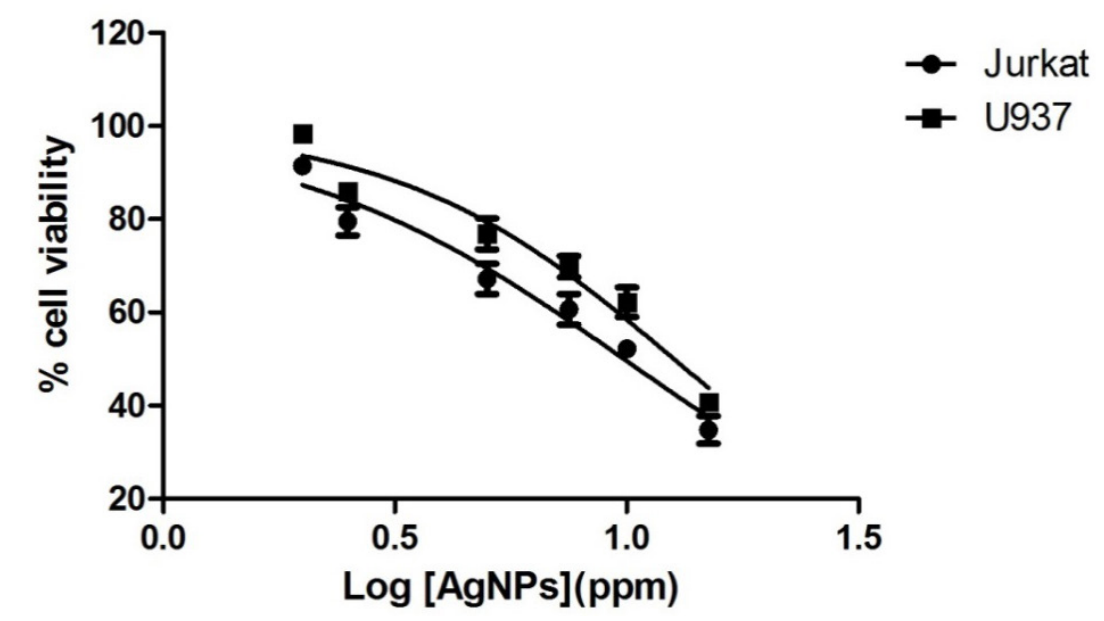

Figure 1. Inhibition of leukemic cells (Jurkat and U937) proliferation by silver nanoparticles (AgNPs). Jurkat and U937 cells were treated with $2.5-15$ ppm of AgNPs for $24 \mathrm{~h}$. Cell viability was analyzed by XTT assay. Data are reported as means $\pm \mathrm{SE}$ of three independent experiments. 


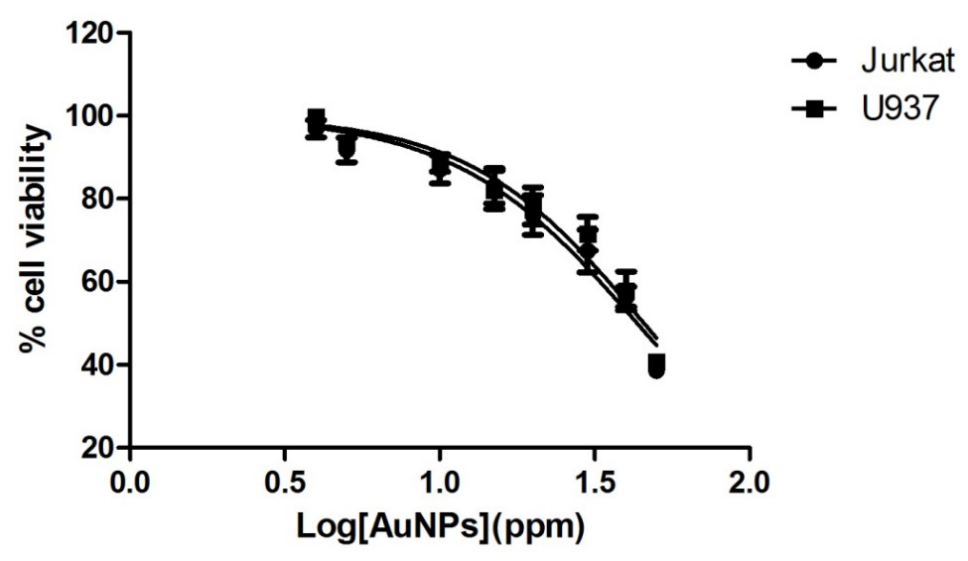

Figure 2. Inhibition of leukemic cells (Jurkat and U937) proliferation by gold nanoparticles (AuNPs). Jurkat and U937 cells were treated with 5-50 ppm of AuNPs for $24 \mathrm{~h}$. Cell viability was analyzed by XTT assay. Data are reported as means $\pm \mathrm{SE}$ of three independent experiments.

In this experiment, we determined whether sodium citrate and PVP (vehicle control) inhibited the proliferation of leukemic cells (Jurkat and U937). The results showed that sodium citrate and PVP did not inhibit proliferation of leukemic cells (data not shown).

\section{Effect of AgNPs and AuNPs on IL-2, TNF- $\alpha$, and IL-6 production}

In this study, we analyzed the expression of cytokine production in leukemic cell lines (Jurkat and U937). Both leukemic cell lines were treated with different concentrations of AgNPs, AuNPs, and vehicle control for $24 \mathrm{~h}$.

\section{Effect of AgNPs and AuNPs on inhibition of PMA/PHA-induced IL-2 and TNF- $\alpha$ production in Jurkat cells}

Jurkat cells were pretreated with different concentrations of AgNPs, below the $\mathrm{IC}_{50}$ $(9.8 \mathrm{ppm})$ for $12 \mathrm{~h}$. Next, PMA/PHA was added and then incubated for additional $12 \mathrm{~h}$. Using an ELISA, we found no significant effect on IL-2 production (data not shown). However, AgNps significantly decreased TNF- $\alpha$ production compared to PMA/PHA alone (Figure 3 ). We found that AgNPs inhibited PMA/PHA-stimulated TNF- $\alpha$ production in a dose-dependent manner. Next, we investigated whether different concentrations of AuNPs below the $\mathrm{IC}_{50}(43.3$ ppm) caused significant decrease in the release of IL-2 from Jurkat cells (Figure 4). However, AuNPs caused no significant decrease in TNF- $\alpha$ production (data not shown).

\section{Effect of AgNPs and AuNPs on inhibition of LPS-induced IL-6 and TNF- $\alpha$ produc- tion in $\mathbf{U} 937$ cells}

U937 cells were pretreated with different concentrations of AgNPs, below the $\mathrm{IC}_{50}(12.6$ $\mathrm{ppm}$ ) for $12 \mathrm{~h}$. Next, LPS was added and incubated for additional $12 \mathrm{~h}$. Using ELISA, we found no significant effect on IL-6 and TNF- $\alpha$ production (data not shown). Next, we investigated dif- 
ferent concentrations of AuNPs below the $\mathrm{IC}_{50}(45.6 \mathrm{ppm})$. We found that AuNPs significantly decreased the release of IL-6 (Figure 5) and increased TNF- $\alpha$ production (Figure 6) in U937 cells.

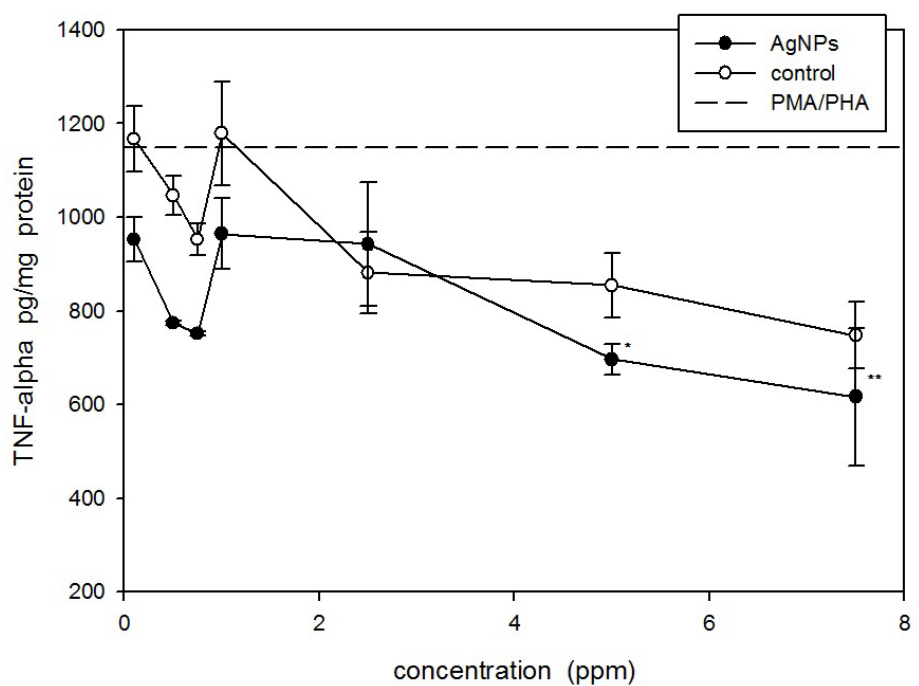

Figure 3. Effect of AgNPs on inhibition of PMA/PHA-induced IL-2 and TNF- $\alpha$ production. Jurkat cells were treated with with 0 to $7.5 \mathrm{ppm}$ of AgNPs, sodium citrate and polyvinyl pyrrolidone (PVP) (vehicle control) for $12 \mathrm{~h}$ and then activated with PMA/PHA for further $12 \mathrm{~h}$. TNF- $\alpha$ production was analyzed by ELISA. Data are reported as means \pm SE from three independent experiments. Statistical analysis was carried out with one-way ANOVA followed by the Tukey multiple comparison test compared with positive controls (PMA/PHA) $\left({ }^{*} \mathrm{P}<0.05,{ }^{* *} \mathrm{P}<0.01\right)$.

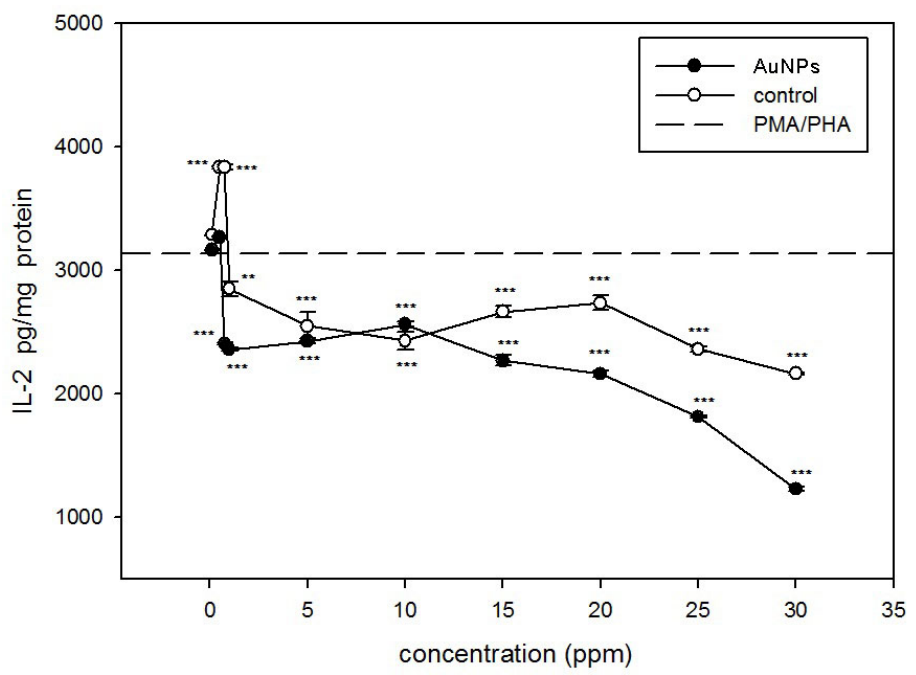

Figure 4. Effect of AuNPs on inhibition of PMA/PHA-induced IL-2 and TNF- $\alpha$ production. Jurkat cells were treated with 0 to $30 \mathrm{ppm}$ of AuNPs, sodium citrate and polyvinyl pyrrolidone (PVP) (vehicle control) for $12 \mathrm{~h}$ and then activated with PMA/PHA for further $12 \mathrm{~h}$. IL-2 production was analyzed by ELISA. Data are reported as means \pm SE from three independent experiments. Statistical analysis was carried out with one-way ANOVA followed by the Tukey multiple comparison test compared with positive controls (PMA/PHA) $(* * \mathrm{P}<0.01, * * * \mathrm{P}<0.001)$. 


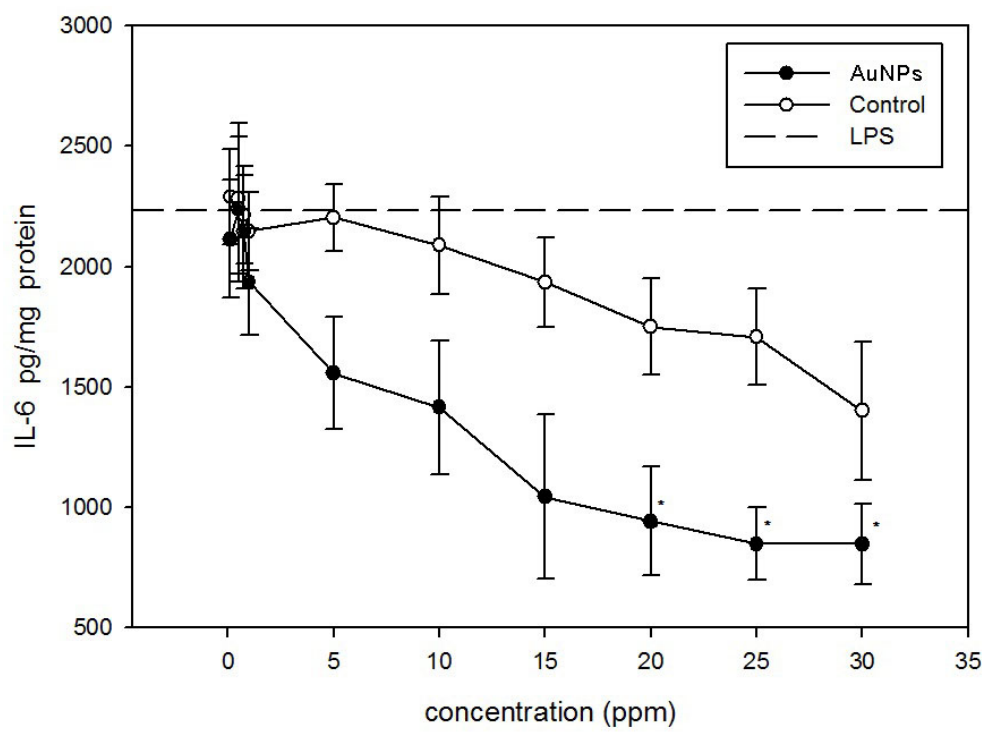

Figure 5. Effect of AuNPs on inhibition of LPS-induced IL-6 and TNF- $\alpha$ production. U937 cells were treated with 0 to $30 \mathrm{ppm}$ of AuNPs, sodium citrate and polyvinyl pyrrolidone (PVP) (vehicle control) for $12 \mathrm{~h}$ and then activated with LPS for further $12 \mathrm{~h}$. IL-6 production was analyzed by ELISA. Data are reported as means \pm SE from three independent experiments. Statistical analysis was carried out with one-way ANOVA followed by the Tukey multiple comparison test compared with positive controls (LPS) $(* \mathrm{P}<0.05)$.

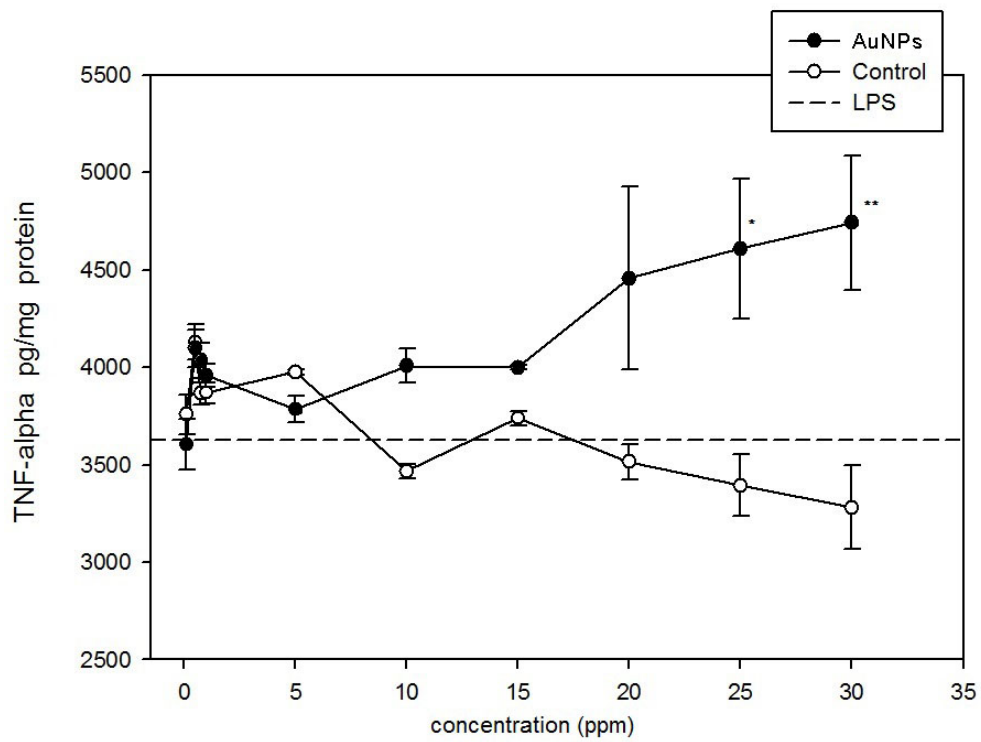

Figure 6. Effect of AuNPs on inhibition of LPS-induced IL-6 and TNF- $\alpha$ production. U937 cells were treated with 0 to $30 \mathrm{ppm}$ of AuNPs, sodium citrate and polyvinyl pyrrolidone (PVP) (vehicle control) for $12 \mathrm{~h}$ and then activated with LPS for further $12 \mathrm{~h}$. TNF- $\alpha$ production was analyzed by ELISA. Data are reported as means \pm SE from three independent experiments. Statistical analysis was carried out with one-way ANOVA followed by the Tukey multiple comparison test compared with positive controls (LPS) $(* \mathrm{P}<0.05, * * \mathrm{P}<0.01)$. 


\section{Effect of AgNPs and AuNPs on MAPK activation and expression in leukemic cells}

In our previous results, we showed that AgNPs and AuNPs induced cytokine release from the leukemic cells. As the MAPK pathway is involved in cytokine production, we further investigated the effects of AgNPs and AuNPs on ERK and JNK proteins in leukemic cells. Concentrations of $7.5 \mathrm{ppm}$ AgNPs and $25 \mathrm{ppm}$ AuNPs were used to treat cells to investigate ERK and JNK protein expression at different time points using western blot analysis. Protein expression level was analyzed based on the intensity of the protein bands from 3 independent experiments.

\section{Effect of AgNPs and AuNPs on ERK pathway in Jurkat cells}

From our previous results, we showed that AgNPs inhibited TNF- $\alpha$ production and AuNPs inhibited IL-2 production. We suspected that inhibition of IL-2 and TNF- $\alpha$ release involved the MAPK pathway. Jurkat cells were treated with AgNPs $7.5 \mathrm{ppm}$ or control (sodium citrate and PVP) for $5 \mathrm{~min}$ to $24 \mathrm{~h}$ and the expression of p-ERK1/2, ERK, and $\beta$-actin was analyzed using western blot analysis (Figure 7A and B). The data showed that the relative level of ERK in the cells treated with AgNPs $7.5 \mathrm{ppm}$ was suppressed at all time points compared to those of control (Figure 7C). Although p-ERK expression was reduced, likely because of the lack of ERK protein at most time points (Figure 7D), the relative ratio of p-ERK1/2/ERK protein level was significantly decreased from 5 to $30 \mathrm{~min}$, suggesting that non-phosphorylated ERK was observed at these time points (Figure 7E).

Next, we studied the effects of AuNPs on p-ERK1/2 and ERK expression in Jurkat cells. Cells were treated with $25 \mathrm{ppm}$ AuNPs or control for $5 \mathrm{~min}$ to $24 \mathrm{~h}$. Western blot analysis revealed expression of p-ERK1/2, ERK, and $\beta$-actin (Figure 8A and B). The results showed that $25 \mathrm{ppm}$ AuNPs increased ERK expression compared to the control at all time points (Figure $8 \mathrm{C}$ ). Despite the increase in ERK protein, the relative ratio of the $\mathrm{p}$-ERK1/2/ERK protein level was significantly reduced at $5 \mathrm{~min}$ to $1 \mathrm{~h}$, suggesting that phosphorylated ERK $1 / 2$ is suppressed at these time points (Figure 8D and E).

\section{Effect of AuNPs on JNK pathway in U937 cells}

We showed in our previous results that AuNPs inhibited IL-6 production and activated TNF- $\alpha$ production release, which may be involved in the MAPK pathway. U937 cells were treated with $25 \mathrm{ppm}$ AuNPs or control (sodium citrate and PVP) for 5 min to $24 \mathrm{~h}$. Western blot analysis showed expression of p-JNK (46 and $54 \mathrm{kDa}$ ), JNK (46 and $54 \mathrm{kDa}$ ), and $\beta$-actin (45 kDa) (Figure 9A, B). The data showed that JNK expression level did not changed with AuNPs treatment at any time points (Figure 9C), whereas AuNPs inhibited pJNK expression at 5 to 30 min compared with to the control (Figure 9D and E).

\section{DISCUSSION}

The anti-proliferation activities of AgNPs and AuNPs on many cancerous cells have been studied in vitro, including human hepatoma HepG2 cells, human lung cancer cells, and 
A

A Sodium citrate + PVP $7.5 \mathrm{ppm}$

Time C $5 \mathrm{~m} 15 \mathrm{~m} 30 \mathrm{~m} 1 \mathrm{~h} 3 \mathrm{~h} 6 \mathrm{~h} 12 \mathrm{~h} 24 \mathrm{~h}$

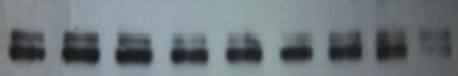

P.ERK 12

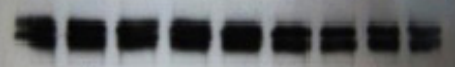

ERK 12

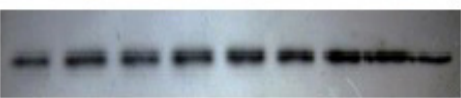

actin

B

AgNps $7.5 \mathrm{ppm}$

Time

C $5 \mathrm{~m} 15 \mathrm{~m} \mathrm{30m} 1 \mathrm{~h} 3 \mathrm{~h} 6 \mathrm{~h} 12 \mathrm{~h} 24 \mathrm{~h}$

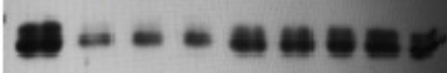

p-ERK $1 / 2$

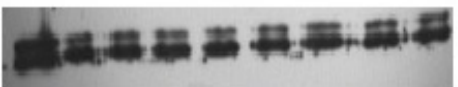

\section{ERK $1 / 2$}

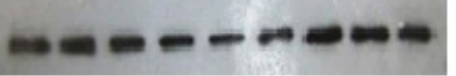

actin

C

Jurkat cell

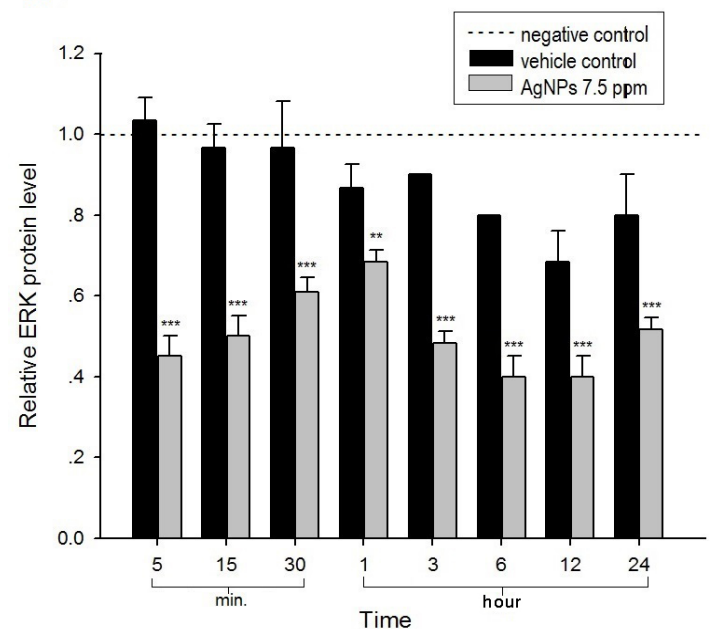

Figure 7. Western blot analysis of the effect of AgNPs on the activity and expression of ERK pathway proteins in Jurkat cells. Cells were treated with AgNPs 7.5 ppm or vehicle control (sodium citrate or PVP) for 5 min to 24 h. Lane $C=$ negative control (untreated cells) at $24 \mathrm{~h}$. A. Expression of p-ERK1/2 (42, $44 \mathrm{kDa})$, ERK1/2 (42, 44 $\mathrm{kDa})$, and actin $(45 \mathrm{kDa})$ after treatment with sodium citrate and PVP $7.5 \mathrm{ppm}$. B. Expression of p-ERK1/2 (42, 44 $\mathrm{kDa})$, ERK1/2 $(42,44 \mathrm{kDa})$ and actin $(45 \mathrm{kDa})$ after treatment with AgNPs $7.5 \mathrm{ppm}$. C. D. E. Data represent the relative $\mathrm{p}$-ERK1/2, ERK and p-ERK1/2/ERK protein levels, and are reported as means $\pm \mathrm{SE}$ from three independent experiments. Statistical analyses were carried out with one-way ANOVA followed by the Tukey multiple comparison test compared with vehicle control (sodium citrate and PVP) $(* \mathrm{P}<0.05, * * \mathrm{P}<0.01, * * * \mathrm{P}<0.001)$.

Continued on next page 
Figure 7. Continued.
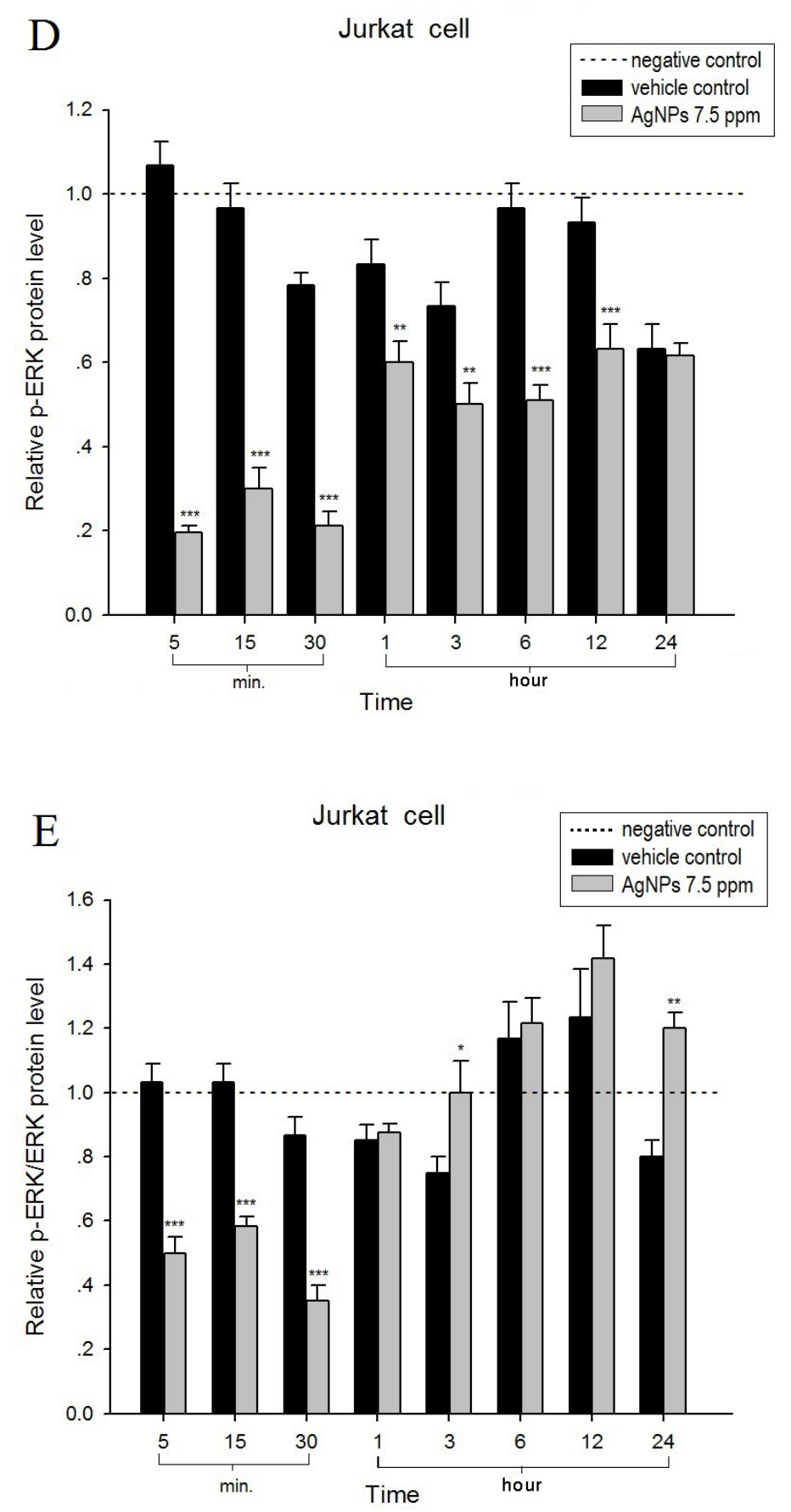
A

\section{Sodium citrate + PVP $25 \mathrm{ppm}$}

Time

C $5 \mathrm{~m} 15 \mathrm{~m} 30 \mathrm{~m} 1 \mathrm{~h} 3 \mathrm{~h} 6 \mathrm{~h} 12 \mathrm{~h} 24 \mathrm{~h}$

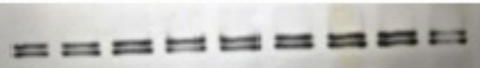

p-ERK $1 / 2$

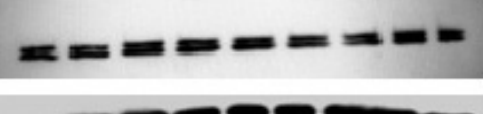

ERK $1 / 2$

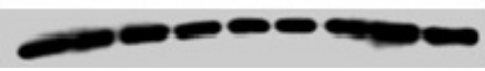

actin

B

AuNPs $25 \mathrm{ppm}$

Time

C $5 \mathrm{~m} 15 \mathrm{~m} 30 \mathrm{~m} 1 \mathrm{~h} 3 \mathrm{~h} 6 \mathrm{~h} 12 \mathrm{~h} 24 \mathrm{~h}$

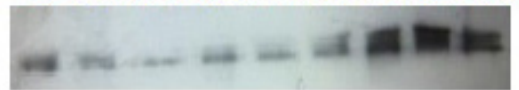

p-ERK $1 / 2$

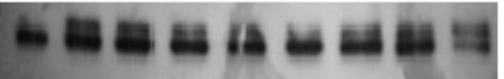

ERK $1 / 2$

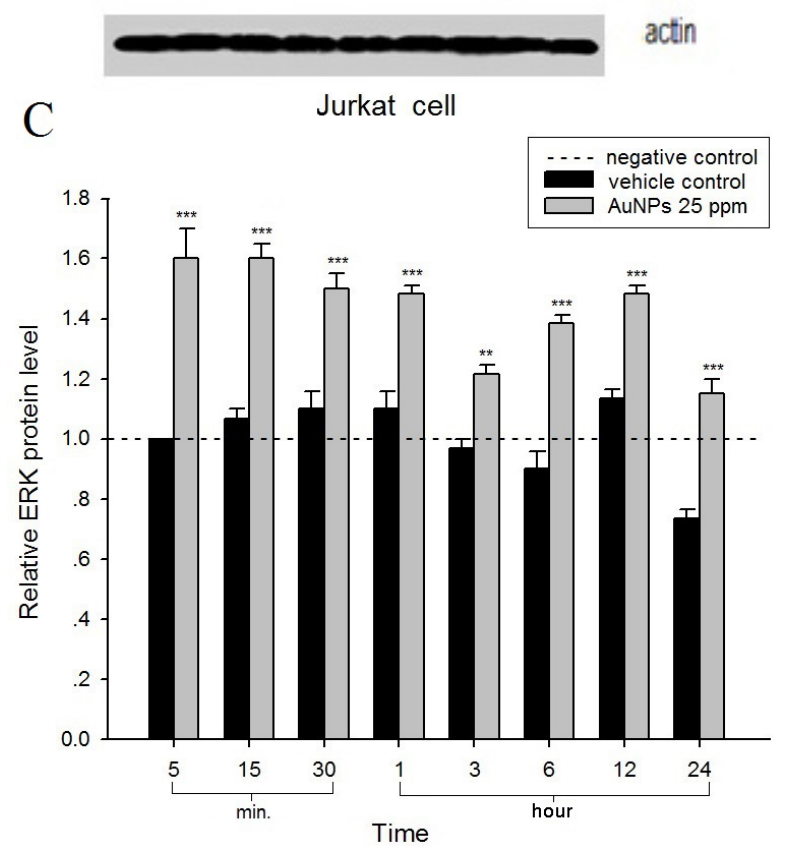

Figure 8. Western blot analysis of the effect of AgNPs on the activity and expression of ERK pathway proteins in Jurkat cells. Cells were treated with AuNPs $25 \mathrm{ppm}$ or vehicle control (sodium citrate and PVP) for 5 min to $24 \mathrm{~h}$. Lane $C=$ negative control (untreated cells) at $24 \mathrm{~h}$. A. Expression of p-ERK 1/2 (42, $44 \mathrm{kDa})$, ERK 1/2 (42, $44 \mathrm{kDa})$ and actin $(45 \mathrm{kDa})$ after treatment with sodium citrate and PVP $25 \mathrm{ppm}$. B. Expression of p-ERK 1/2 (42, $44 \mathrm{kDa})$, ERK 1/2 $(42,44 \mathrm{kDa})$ and actin $(45 \mathrm{kDa})$ after treatment with AuNPs $25 \mathrm{ppm}$. C. D. E. Relative p-ERK, ERK and $p$-ERK/ERK protein levels. Data are reported as means \pm SE from three independent experiments. Statistical analysis was carried out with one-way ANOVA followed by the Tukey multiple comparison test compared with sodium citrate and PVP (vehicle control) $(* \mathrm{P}<0.05, * * \mathrm{P}<0.01, * * * \mathrm{P}<0.001)$.

Continued on next page 
Figure 8. Continued.
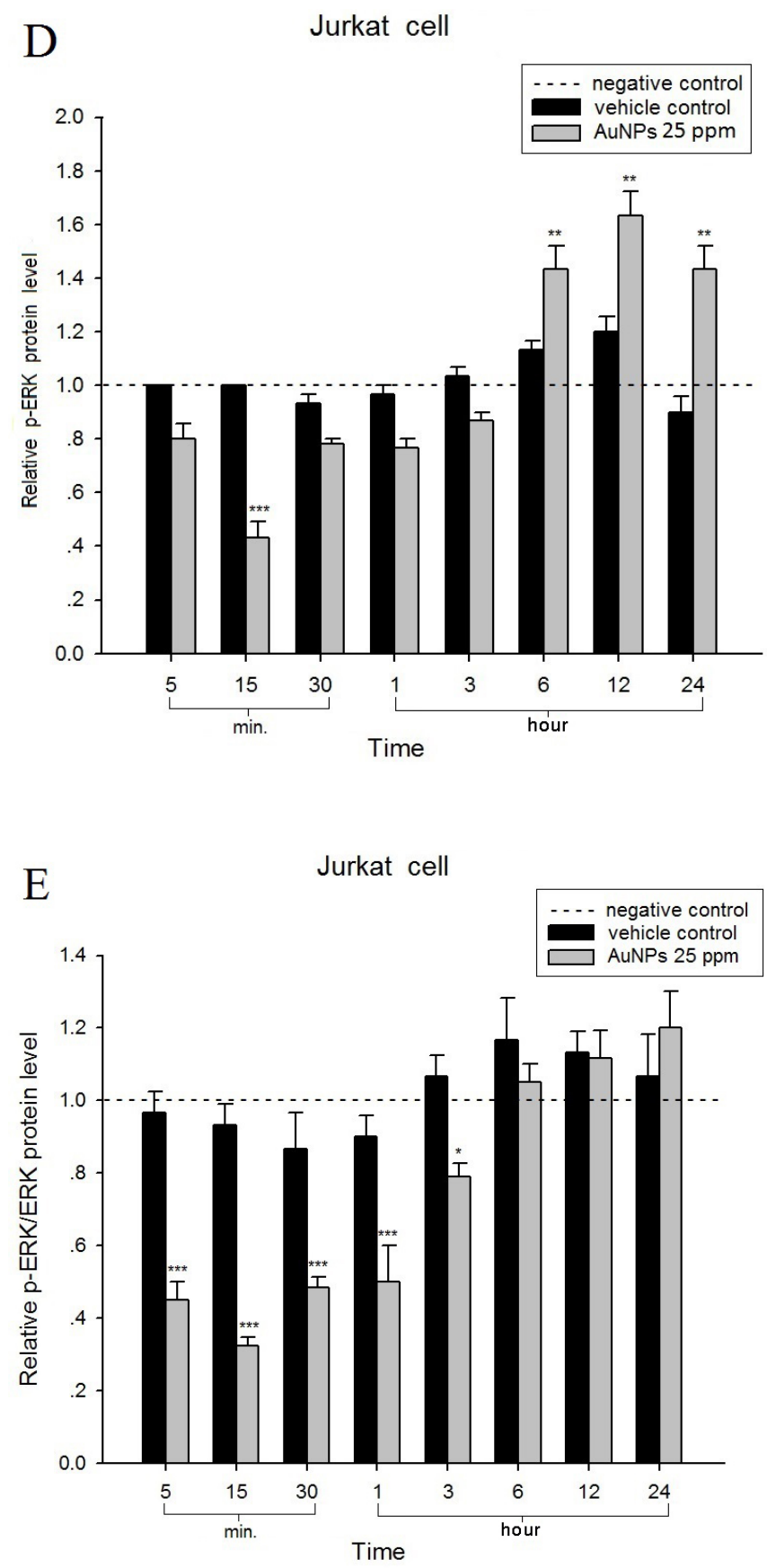

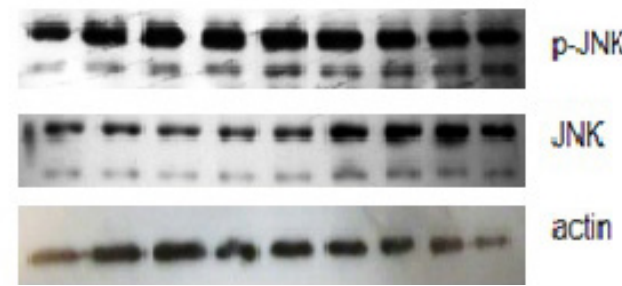

actin

$\mathrm{B}$

AuNPs $25 \mathrm{ppm}$

Time

C $5 \mathrm{~m} 15 \mathrm{~m} 30 \mathrm{~m} 1 \mathrm{~h} 3 \mathrm{~h} 6 \mathrm{~h} 12 \mathrm{~h} 24 \mathrm{~h}$

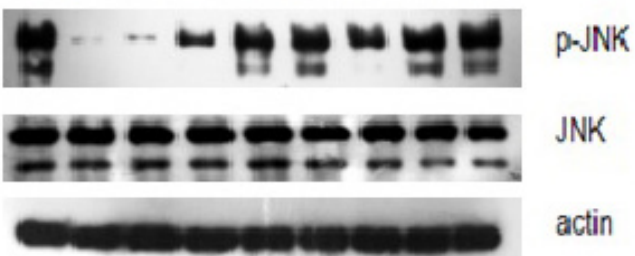

C

U 937 cell

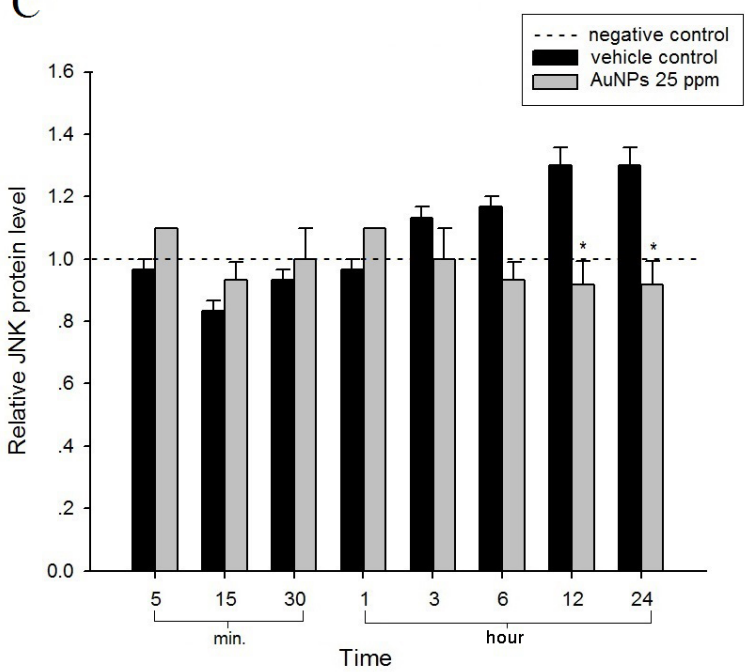

Figure 9. Western blot analysis of the effect of AuNPs on the activity of JNK pathway in U937 cells. Cells were treated with AuNPs $25 \mathrm{ppm}$ or vehicle control (sodium citrate and PVP) for $5 \mathrm{~min}$ to $24 \mathrm{~h}$. Lane C = negative control (untreated cells) at $24 \mathrm{~h}$. A. Expression of p-JNK (46, $54 \mathrm{kDa}), \mathrm{JNK}(46,54 \mathrm{kDa})$ and actin $(45 \mathrm{kDa})$ after treatment with sodium citrate and PVP $25 \mathrm{ppm}$. B. Expression of p-JNK (46, $54 \mathrm{kDa})$, JNK $(46,54 \mathrm{kDa})$ and actin $(45 \mathrm{kDa})$ after treatment with AuNPs $25 \mathrm{ppm}$. C. D. E. Data represent the relative p-JNK, JNK and p-JNK/JNK protein levels and are reported as means \pm SE from three independent experiments. Statistical analysis was carried out with one-way ANOVA followed by the Tukey multiple comparison test compared with sodium citrate and PVP (vehicle control) $(* \mathrm{P}<0.05, * * \mathrm{P}<0.01, * * * \mathrm{P}<0.001)$

Continued on next page 
Figure 9. Continued.
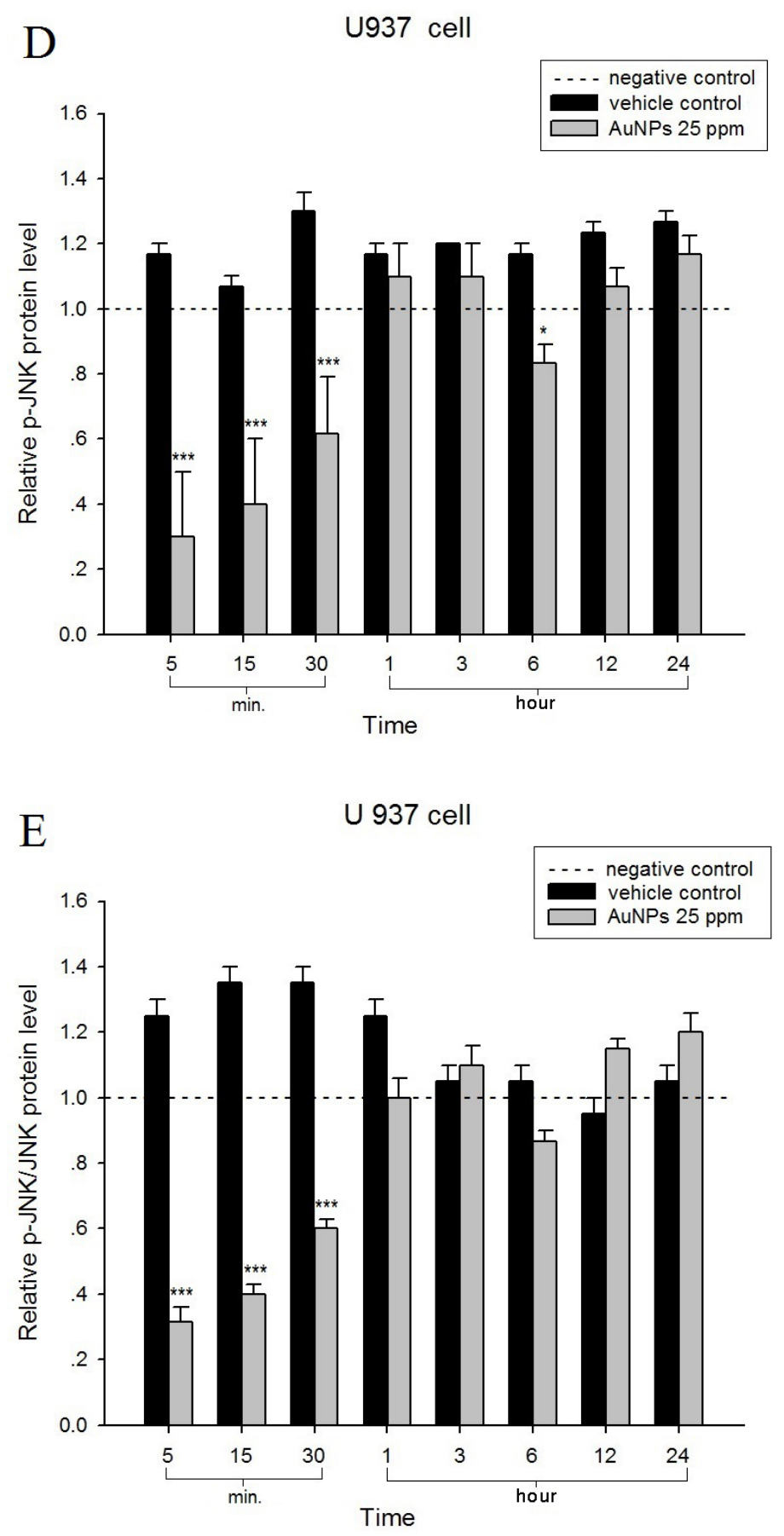

Genetics and Molecular Research 14 (2): 3650-3668 (2015) 
6 acute myeloid leukemia cell lines, showing $\mathrm{IC}_{50}$ values ranging from $0.5-20 \mathrm{ppm}$ of AgNps (Kim et al., 2009; Zhou and Wang, 2012; Guo et al., 2013). AuNPs inhibited the proliferation of multiple myeloma cell lines and human lung adenocarcinoma cells with $\mathrm{IC}_{50}$ values ranging from 5-60 ppm (Bhattacharya et al., 2007; Choi et al., 2012). The amount of inhibition depends on the cell type, dose, and length of treatment.

Our study showed that AgNPs inhibited the proliferation of Jurkat cells and U937 cells with $\mathrm{IC}_{50}$ values of 9.8 and $12.6 \mathrm{ppm}$, respectively. At higher concentrations, AuNPs inhibited proliferation of Jurkat ( $\mathrm{IC}_{50}$ of $\left.43.3 \mathrm{ppm}\right)$ and $\mathrm{U} 937$ cells $\left(\mathrm{IC}_{50}\right.$ of $\left.45.6 \mathrm{ppm}\right)$.

AgNPs showed more significant inhibitory efficacy compared to AuNPs because AgNPs are more easily oxidized than AuNPs, leading to oxidative stress in the cell membrane (Bogumiła et al., 2013). We also demonstrated that AgNPs and AuNPs affect PMA/PHAinduced cytokine production in Jurkat cells and LPS-induced cytokine production in U937 cells. Cytokines are signaling molecules that mediate and regulate cellular activities. IL-2 and IL-6 regulate cell proliferation and cytokine secretion, whereas TNF- $\alpha$ regulates immunity, inflammation, and apoptosis (Bradley, 2008; O'Shea et al., 2008). Other studies have found that AgNPs and AuNPs upregulated cytokine expression in other cell types (Yen et al., 2009; Khan et al., 2013). However, we found that AgNPs inhibit TNF- $\alpha$ in Jurkat cells and AuNPs inhibit IL-2 and IL-6 in Jurkat and U937 cells in a concentration-dependent manner. Suppression of IL-2 and IL-6, which are important for regulating cell proliferation in Jurkat and U937 cells, is a potential mechanism that inhibits cell proliferation. However, AgNPs did not inhibit IL-2 and IL-6 and have higher toxicity than AuNPs based on the $\mathrm{IC}_{50}$ values, suggesting that mechanisms other than antiproliferation reduce cell survival. Interestingly, TNF- $\alpha$ was reported to have the opposite effect in different cell types, in which TNF- $\alpha$ was inhibited by AgNPs in Jurkat cells but stimulated by AuNPs in U937 cells. Inhibition of TNF- $\alpha$ may lead to reduced cellular responses and activities, whereas induction may lead to cell apoptosis. Whether through inhibition or induction of TNF- $\alpha$ in different cell types, cell survival is reduced.

Previous studies reported the effects of nanoparticles on the MAPK signaling pathway in many cell types. AgNPs induced apoptosis through reactive oxygen species and JNK-MAPK via the mitochondria pathway in NIH3T3 fibroblast cells (Hsin et al., 2008). AgNPs can increase the expression of p38 in Caenorhabditis elegans (Lim et al., 2012), AgNPs decreased ERK signaling, and AuNPs significantly reduced p-ERK levels in epithelial cells (Comfort et al., 2011). In this study, we investigated the effects of AgNPs and AuNPs on MAPK signaling pathway activities and expression, focusing on ERK and JNK, in leukemic cells. Our results showed that AgNPs suppressed ERK, whereas AuNPs increased ERK expression. However, based on the ratio of p-ERK/ERK, both AgNPs and AuNPs attenuated levels of ERK phosphorylation for the first $30 \mathrm{~min}$ after treatment in Jurkat cells. ERK signaling is known to induce cell proliferation and cell survival. The association between cytokine production and the MAPK signaling pathway has been described previously; IL-2 acts through ERK signaling in proliferation and cell survival (Gaffen, 2001). AuNPs inhibit IL-2 and reduce ERK phosphorylation, indicating that anti-proliferation of Jurkat cells is caused by suppression of IL-2 production via the ERK pathway. Reduction of TNF- $\alpha$ by AgNPs likely also involves the ERK pathway. In previous studies, TNF- $\alpha$ activated NF-kB to regulate FLICE-like inhibitory protein long form as a mediator of ERK1/2 phosphorylation, leading to the promotion of cell survival (Marques-Fernandez et al., 2013). Other pathway proteins may also be involved in nanoparticle inhibition of IL-2 and TNF- $\alpha$ production such as NF-kB or p38, for which further studies should be conducted. Furthermore, AgNPs and AuNPs did not change the activity or 
expression of JNK protein (data not shown), suggesting that JNK is not involved in nanoparticle inhibition of cytokine production in Jurkat cells.

JNK signaling suppresses tumor cells possibly by inducing apoptosis (Kennedy et al., 2003). In contrast, JNK signaling may activate NF-kB, leading to the suppression of apoptosis (Bubici et al., 2004). In addition, TNF- $\alpha$ can promote cell survival, previous studies have shown that IL-6 expression, regulated by JNK, mediates NF-kB-mediated cell survival in renal epithelial cells (de Haij et al., 2005). Our results showed AuNPs inhibited IL-6, stimulated TNF- $\alpha$, and reduced JNK phosphorylation in U937 cells, while AuNPs did not affect ERK protein (data not shown). This suggests that the JNK pathway, but not ERK, is involved in cytokine production, particularly IL-6, resulting in anti-proliferation of U937 cells. TNF- $\alpha$ and JNK are known to modulate apoptosis, but the roles of JNK signaling in relation to TNF- $\alpha$ production to promote cell death and survival is not clearly understood. Stimulation of TNF- $\alpha$ by AuNPs may involve other signal pathway proteins such as NF-kB, activator protein 1, and Bid.

In this report, we investigated whether AgNPs and AuNPs had anti-leukemia effects against human leukemic cell lines. Both AgNPs and AuNPs showed effects on cytokine production via either the ERK or JNK pathway, depending on the cell type and nanoparticle type, resulting in reduction of cell growth. For leukemic T-cells, Jurkat cells responded to both AgNPs and AuNPs via ERK, whereas monocytic U937 cells responded to only AuNPs via the JNK pathway. This inhibition of cytokines and reduction of phosphorylated ERK and JNK is unlikely to have resulted from nanoparticle-induced toxicity of the cells because the concentrations of AgNPs and AuNPs used were well below the $\mathrm{IC}_{50}$. Other signaling pathway proteins cannot be ruled out as having roles in anti-proliferation. Our data provides useful information regarding possible treatments since partial mechanisms of anti-proliferation in each leukemic cell type are known. In addition to anti-proliferation properties, nanoparticles may process other properties, which could damage cell functions or even induce cell death or apoptosis, and further studies should be carried out to examine this. Moreover, the effects of nanoparticles on normal blood cells should be also investigated to evaluate cell toxicity in normal cells. Our findings suggest that nanoparticles can be applied for alternative co-treatment, combined with conventional treatments for leukemia.

\section{ACKNOWLEDGMENTS}

Research supported by the 90th Anniversary of Chulalongkorn University Fund (Ratchadaphiseksomphot Endowment Fund) (Grant \#19-3-2012), the 100th Anniversary of Chulalongkorn University Fund and Center for Research and Development in Molecular Hematology Sciences in the Chulalongkorn University Centenary Academic Development Project. Chalisa Parnsamut received a tuition fee scholarship and teaching assistant fellowship from the Department of Clinical Microscopy, Faculty of Allied Health Sciences, Chulalongkorn University. We thank Center for Research and Development in Molecular Hematology Sciences in the Chulalongkorn University for providing laboratory space and equipment, and Dr. James M. Brimson for advice in our research and for help drafting our manuscript.

\section{REFERENCES}

Alarcon EI, Udekwu K, Skog M, Pacioni NL, et al. (2012). The biocompatibility and antibacterial properties of collagen- 
stabilized, photochemically prepared silver nanoparticles. Biomaterials 33: 4947-4956.

Arvizo RR, Rana S, Miranda OR, Bhattacharya R, et al. (2011). Mechanism of anti-angiogenic property of gold nanoparticles: role of nanoparticle size and surface charge. Nanomedicine 7: 580-587.

Bhattacharya R, Patra CR, Verma R and Kumar S (2007). Gold nanoparticles inhibit the proliferation of multiple myeloma cells. Adv. Mater. 19: 711-716.

Bogumila R, Andrea H, Andreas L and Kenneth AD (2013). Mechanisms of silver nanoparticle release, transformation and toxicity: A critical review of current knowledge and recommendations for future studies and applications. Materials 6: 2295-2350.

Bradley JR (2008). TNF-mediated inflammatory disease. J. Pathol. 214: 149-160.

Brown G, Hughes PJ, Ceredig R and Michell RH (2012). Versatility and nuances of the architecture of haematopoiesis Implications for the nature of leukaemia. Leuk. Res. 36: 14-22.

Bubici C, Papa S, Pham CG, Zazzeroni F, et al. (2004). NF-kappaB and JNK: an intricate affair. Cell Cycle 3: 1524-1529.

Chang L and Karin M (2001). Mammalian MAP kinase signalling cascades. Nature 410: 37-40.

Choi SY, Jeong S, Jang SH, Park J, et al. (2012). In vitro toxicity of serum protein-adsorbed citrate-reduced gold nanoparticles in human lung adenocarcinoma cells. Toxicol. In Vitro 26: 229-237.

Comfort KK, Maurer EI, Braydich-Stolle LK and Hussain SM (2011). Interference of silver, gold, and iron oxide nanoparticles on epidermal growth factor signal transduction in epithelial cells. ACS Nano 5: 10000-10008.

de Haij S, Bakker AC, van der Geest RN, Haegeman G, et al. (2005). NF-kappaB mediated IL-6 production by renal epithelial cells is regulated by c-jun NH2-terminal kinase. J. Am. Soc. Nephrol. 16: 1603-1611.

Dhillon AS, Hagan S, Rath O and Kolch W (2007). MAP kinase signalling pathways in cancer. Oncogene 26: 3279-3290.

Eom HJ and Choi J (2010). p38 MAPK activation, DNA damage, cell cycle arrest and apoptosis as mechanisms of toxicity of silver nanoparticles in Jurkat T cells. Environ. Sci. Technol. 44: 8337-8342.

Eustis S (2006). Gold and Silver Nanoparticles: Characterization of Their Interesting Optical Properties and the Mechanism of Their Photochemical Formation. Doctoral thesis, Department of Chemistry and Biology Georgia Institute of Technology. Atlanta, 290.

Gaffen SL (2001). Signaling domains of the interleukin 2 receptor. Cytokine 14: 63-77.

Guo D, Zhu L, Huang Z, Zhou H, et al. (2013). Anti-leukemia activity of PVP-coated silver nanoparticles via generation of reactive oxygen species and release of silver ions. Biomaterials 34: 7884-7894.

Hsin YH, Chen CF, Huang S, Shih TS, et al. (2008). The apoptotic effect of nanosilver is mediated by a ROS- and JNKdependent mechanism involving the mitochondrial pathway in NIH3T3 cells. Toxicol. Lett. 179: 130-139.

Kennedy NJ, Sluss HK, Jones SN, Bar-Sagi D, et al. (2003). Suppression of Ras-stimulated transformation by the JNK signal transduction pathway. Genes Dev. 17: 629-637.

Khan HA, Abdelhalim MA, Alhomida AS and Al-Ayed MS (2013). Effects of naked gold nanoparticles on proinflammatory cytokines mRNA expression in rat liver and kidney. Biomed. Res. Int. 590730.

Kim S, Choi JE, Choi J, Chung KH, et al. (2009). Oxidative stress-dependent toxicity of silver nanoparticles in human hepatoma cells. Toxicol. In Vitro 23: 1076-1084.

Kyriakis JM and Avruch J (2001). Mammalian mitogen-activated protein kinase signal transduction pathways activated by stress and inflammation. Physiol. Rev. 81: 807-869.

Lim D, Roh JY, Eom HJ, Choi JY, et al. (2012). Oxidative stress-related PMK-1 P38 MAPK activation as a mechanism for toxicity of silver nanoparticles to reproduction in the nematode Caenorhabditis elegans. Environ. Toxicol. Chem. 31: 585-592.

Marques-Fernandez F, Planells-Ferrer L, Gozzelino R, Galenkamp KM, et al. (2013). TNF $\alpha$ induces survival through the FLIP-L-dependent activation of the MAPK/ERK pathway. Cell Death. Dis. 4: e493.

O'Shea JJ, Tato CM and Siegel R (2008). Principles of Immune Recognition: Cytokines and Cytokine Receptors. In: Clinical Immunology. 3rd edn. (Rich RR, Shearer WT, Fleischer TA, Schroeder HW, et al., eds.). Elsevier, Amsterdam.

Panácek A, Kolár M, Vecerová R, Prucek R, et al. (2009). Antifungal activity of silver nanoparticles against Candida spp. Biomaterials 30: 6333-6340.

Piller G (1993). The history of leukemia: a personal perspective. Blood Cells 19: 521-529.

Platanias LC (2003). Map kinase signaling pathways and hematologic malignancies. Blood 101: 4667-4679.

Solomon SD, Bahadory M, Jeyarajasingam AV and Rutkowsky SA (2007). Synthesis and study of silver nanoparticles. J. Chem. Educ. 84: 322.

Turkevich J, Stevenson PC and Hillier J (1951). A study of the nucleation and growth processes in the synthesis of colloidal gold. Discuss. Faraday Soc. 11: 55-75.

Wang H, Qiao X, Chen J and Wang X (2005). Mechanisms of PVP in the preparation of silver nanoparticles. Mater. Chem. Phys. 94: 449-453. 
Wong KK, Cheung SO, Huang L, Niu J, et al. (2009). Further evidence of the anti-inflammatory effects of silver nanoparticles. Chem. Med. Chem. 4: 1129-1135.

Yen HJ, Hsu SH and Tsai CL (2009). Cytotoxicity and immunological response of gold and silver nanoparticles of different sizes. Small 5: 1553-1561.

Yi C, Liu D, Fong CC and Zhang J, et al. (2010). Gold nanoparticles promote osteogenic differentiation of mesenchymal stem cells through p38 MAPK pathway. ACS Nano 4: 6439-6448.

Zhou GQ and Wang WY (2012). Synthesis of silver nanoparticles and their antiproliferation against human lung cancer cells in vitro. Orient. J. Chem. 28: 651. 